\title{
Plug-in Vehicles Car Park Photovoltatic Farm Construction for Cost and Emission Reductions
}

\author{
Tan Ma, Student Member, IEEE, and Osama Mohammed, Fellow, IEEE
}

\begin{abstract}
In this paper, a photovoltatic (PV) farm construction plan for charging plug-in electric vehicles (PEVs) in a workplace parking lot is proposed. The system involves a developed smart power charging controller, an under construction PV farm and a DC distribution bus connected to the AC utility grid. In order to produce enough energy for the daily consumption of a certain number of PEVs at the same time limit the construction cost of the PV farm, the scale of the PV farm should be optimized. A stochastic model of PEVs daily energy consumption is used together with the historical solar irradiance data in this area to find the best scale of the PV farm through genetic algorithm (GA) optimization. Since the output power from the PV farm varies in different environmental situations, energy forecasting and distribution is achieved by using the smart power flow controller. One day period simulation of the hybrid PEVs charging system is done to demonstrate that the proposed plan can effectively support enough power for a certain number of PEVs with the maximum utilization of renewable energy and minimum grid impact.
\end{abstract}

Index Terms - Plug-in electric vehicles, renewable energy integration, smart charging, smart grid, solar energy.

\section{INTRODUCTION}

$\mathrm{P}$ LUG-IN electric vehicles (PEVs) are gaining popularity due to the global call for clean energy. The alarming rate at which global energy reserves are depleting is a major worldwide concern at economic, environmental, industrial, and societal levels. In 2012 , more than $80 \%$ of the energy consumed in the USA was generated by petroleum, natural gas and coal. Renewable energy sources only supplied no more than $8 \%$ of the total energy consumption. Greenhouse gas emissions have greatly changed climate which has potentially serious consequences for human society [1]. Meanwhile, transportation consumed $30 \%$ of the total energy generated in 2012 Therefore, the use of renewable to charge PEVs may become attractive, particularly if emission can be largely reduced and customers would pay less [2] -[3].

Researchers are working toward renewable and alternative energy harvesting from renewable energy resources such as solar and wind to charge PEVs, which can be cost effective without bringing adverse environmental impacts. In [4], a PEVs car park charging hybrid power system model with a photovoltaic (PV) system is proposed. In this model, the impact of charging PEVs to the utility grid is limited, but still the car park needs to get a large amount of energy from the utility grid since the PV farm scale is not the optimal that can fit the certain

The authors are with the Energy Systems Research Laboratory, Department of Electrical and Computer Engineering, Florida International University, Miami, FL 33174 USA (e-mail: mohammed@fiu.edu). number of PEVs properly. Also, how to operate the PV system to maximum the energy output is not covered in the paper. In [5], to realize real-time minimization of the total cost of generating the energy plus the associated grid energy losses, load management solutions for coordinating the charging process of multiple PEVs in smart grid system were proposed. However, the authors did not consider the inclusion of renewable energy source in the system. This holds the implementation of models back since we know that the concept of PEVs is attached to obtaining the power to charge them from renewable energy. Also, the PEVs priority levels classification is not based on their state of charges (SOCs), which cannot guarantee that every PEVs can get energy energy before the next departure.

Short term and long term artificial neural network (ANN) forecasting models of energy production in solar and wind energy are studied in [6] and [7], these models can be used to estimate next period energy output for a certain PV farm. In [8], operation and protection of PV systems in hybrid AC/DC smart grids are discussed, different maximum power points tracking technologies and their advantages and disadvantages is given. This can give the construction of PV farm with both hardware and power flow control support.

In this paper, a construction plan for a car park PV farm to charge 300 PEVs is studied. A stochastic model of PEVs daily energy consumption is proposed based on US drivers' driving patterns. Together with the historical solar irradiance data, the optimal scale of the PV farm that can support proper energy for those 300 PEVs' daily usage is found by using genetic algorithm (GA) optimization. With the short term forecasted output energy from the optimized PV farm based on neural network and the energy requirement from the PEVs in the car park, a fuzzy logical power flow controller is used to control the charging of PEVs to maximize the utilization of energy produced from the PV farm, which will limit the impact of the PEVs charging in this garage to the utility and also greatly reduce the greenhouse gas emissions.

The paper is organized as follows. In Section II, hybrid power system overall description is given. In Section III, PV model and DC-DC converter with maximum power point tracking (MPPT) technique are given. In Section IV, the optimization of PV farm scheduling is achieved based on the PEVs stochastic daily energy requirement model and historical solar irradiance data through a genetic algorithm (GA). Section $\mathrm{V}$, fuzzy logic based real time PEVs charging algorithm is given. Section VI demonstrates the simulation results for the proposed model. Finally, conclusions are drawn in Section VII. 


\section{HYBRID PEVS CHARGING SYSTEM DESCRIPTION}

The hybrid AC/DC PEVs charging system, implemented in the energy system research laboratory, Florida International University, is a DC distribution system that depends mainly on renewable energy generated by $\mathrm{PV}$ to charge local loads and charge PEVs. The diagram of the workplace hybrid car park power system under study is as shown in Fig. 1. It consists of a PV farm to support power for around $300 \mathrm{PEVs}$ ' daily usage through a $300 \mathrm{~V}$ DC bus. This car park power works in the grid connected mode through a bidirectional AC/DC converter, which can let the car park absorb power from the grid if the PV farm can't produce sufficient energy to charge the PEVs or inject power to the grid if the PV farm generates more energy than the PEVs' requirement. To maximize the utilization of the power generated by PV farm to charge the PEVs, a smart power flow management should be designed. Also, in order to minimize the PV farm construction cost, the scale of the PV farm should be optimized so that it can support enough power for the PEVs daily usage with the smallest size. What's more, to maximize the system efficiency, MPPT together with the high efficiency bidirectional converter is needed.

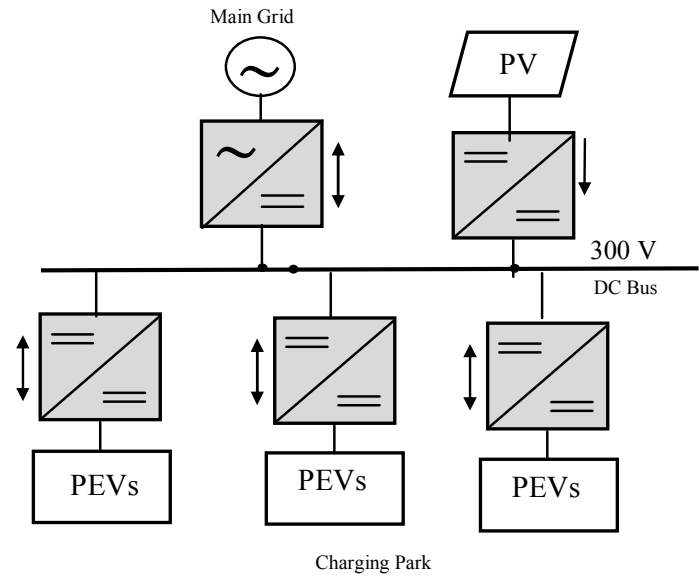

Fig. 1. Schematic diagram of the investigated system

\section{PV MODEL AND MAXIMUM POWER POINT TRACKING}

\section{A. Modeling of PV Panel}

Fig. 2 shows the equivalent circuit of a PV panel with load. Equations (1)-(3) show the mathematic model of the PV panel and its output current [9],[10]. All the parameters are shown in Table I:

$$
\begin{aligned}
& I_{p v}=n_{p} I_{p h}-n_{p} I_{s a t} \cdot\left[\exp \left(\left(\frac{q}{A k T}\right)\left(\frac{V_{p v}}{n_{s}}+I_{p v} R_{s}\right)\right)-1\right] \\
& I_{p h}=\left(I_{s s o}+k i\left(T-T_{r}\right)\right) \cdot \frac{S}{1000} \\
& I_{s a t}=I_{r r}\left(\frac{T}{T r}\right)^{3} \exp \left(\left(\frac{q E_{g a p}}{k A}\right) \cdot\left(\frac{1}{T_{r}}-\frac{1}{T}\right)\right)
\end{aligned}
$$

\section{B. Maximum Power Point Tracking Technique.}

The relation between PV output voltage and current is non-linear, therefore the output voltage of PV panels is dependent on the output power. Moreover, with different solar

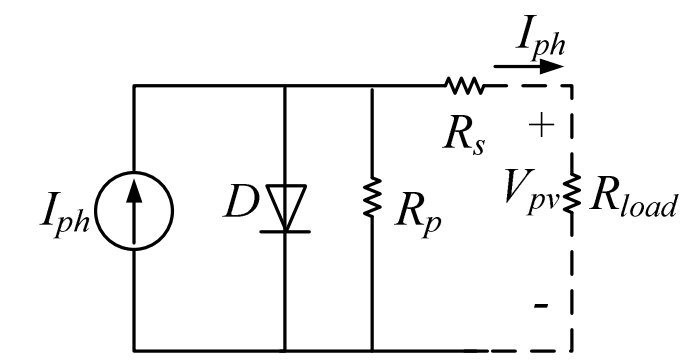

Fig. 2. Equivalent circuit of a PV panel

TABLE I

PARAMETERS FOR PHOTOVOLATIC PANEL

\begin{tabular}{lll}
\hline \hline Symbol & \multicolumn{1}{c}{ Description } & \multicolumn{1}{c}{ Vaule } \\
& & \\
\hline$V_{o c}$ & Rated open circuit voltage & $64.2 \mathrm{~V}$ \\
$I_{p h}$ & Photocurrent & $5.9602 \mathrm{~A}$ \\
$I_{s a t}$ & Module reverse satuation current & $1.1753 \times 10^{-8}$ \\
$q$ & Electron charge & $1.602 \times 10^{-19} \mathrm{C}$ \\
$A$ & Ideality factor & 1.50 \\
$k$ & Boltzman constant & $1.38 \times 10^{-23} \mathrm{~J} / \mathrm{K}$ \\
$R_{s}$ & Series resistance of a PV cell & $0.037998 \Omega$ \\
$R_{p}$ & Parallel resistance of a PVcell & $993.51 \Omega$ \\
$I_{s s o}$ & Short-circuit current & $5.96 \mathrm{~A}$ \\
$k_{i}$ & SC current temperature coefficient & $1.7 \times 10^{-3}$ \\
$T_{r}$ & Reference temperature & $301.18 \mathrm{~K}$ \\
$I_{r r}$ & Reverse saturation current at $T_{r}$ & $2.0793 \times 10^{-6} \mathrm{~A}$ \\
$E_{g a p}$ & Energy of the band gap for silicon & $1.1 \mathrm{eV}$ \\
$n_{p}$ & Number of cells in parallel & 528 \\
$n_{s}$ & Number of cells inseries & 480 \\
$S$ & Solar radiation level & $0 \sim 1000 \mathrm{~W} / \mathrm{m}^{2}$ \\
$T$ & Surface temperature of the PV & $350 \mathrm{~K}$ \\
\hline \hline
\end{tabular}

irradiations and temperatures, the output power from a unit PV panel follows different power-voltage curves. Fig. 3 shows the non-linear electric characteristics of a SunPower SPR-305-WHT solar panel. It is clear that under different solar irradiations, the maximum power points of the power-voltage curves are associated with different output voltages. Since the voltage of the DC bus is constant at $300 \mathrm{~V}$, a DC-DC boost converter with maximum power point tracking (MPPT) functionality is needed to maximize the output power generated by PV farm.

In this paper, perturbation and observe $(\mathrm{P} \& \mathrm{O})$ method is used to track he maximum power point. The algorithm utilizes the values of the input current and voltage to calculate the power. The values of the voltage and power at the $k^{\text {th }}$ iteration
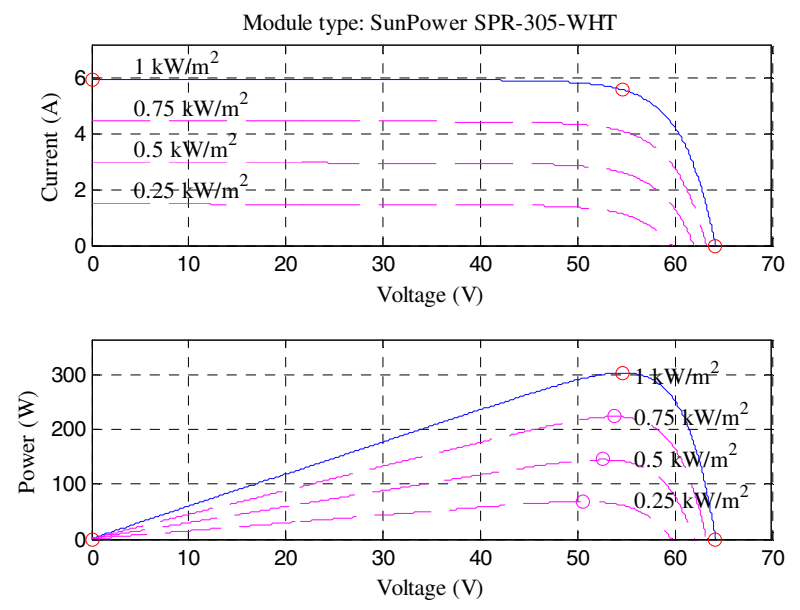

Fig. 3 I-V and P-V curves for PV panel Sumpower SPR-305-WHT 


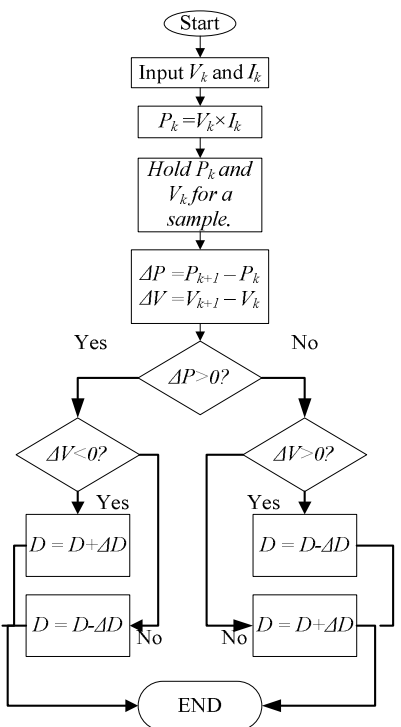

Fig. 4 Flow chart of P\&O MPPT method.

$\left(P_{k}\right)$ are stored, then the same values are measured and calculated for the $(k+1)^{\text {th }}$ iteration $\left(P_{k+1}\right)$. The power difference between the two iterations $(\Delta P)$ is calculated. The converter should increase the PV panel output voltage if $\Delta P$ is positive and decrease the output voltage if $\Delta P$ is negative, which finally will adjust the duty cycle. The PV panel reaches the maximum power point when $\Delta P$ is around zero. The flow chart of the P\&Q MPPT algorithm is given is Fig. 4.

\section{PV FARM SCALE OPTIMIZATION}

\section{A. PEVs energy consumption model}

To find the best scale of the PV farm, a stochastic model of PEVs daily energy consumption for PEVs parking in this car park should be found. The $300 \mathrm{PEVs}$ are classified in four different groups with different sizes, battery capacities and energy consumptions per mile. The specific detail is shown in Table II. The owners of PEVs are requested to set the next departure time whenever they connect their vehicles to the system, and the system will make a record.

The estimated power demanded by each individual PEV $\left(\hat{p}_{P E V, i}\right)$ can be represented by the equation (4). Where $\hat{P}_{P E V, i}$ is the estimated power demanded by the $i^{\text {th }} \mathrm{PEV}, \hat{M}_{d}$ is the estimated number of miles driven daily, $E_{m}$ is the energy

$$
\text { TABLE II }
$$

PARAMETERS For PHEVS IN DIFFERENT SIZE

\begin{tabular}{cccc}
\hline \hline PHEVs model & Percentage & $\begin{array}{c}\text { Battery capacity } \\
(\mathrm{kWh})\end{array}$ & $\begin{array}{c}\text { Energy consumption } \\
\text { per mile }(\mathrm{kWh} / \mathrm{mile})\end{array}$ \\
\hline compact sedan & $32.5 \%$ & $10-20$ & 0.2 \\
$\begin{array}{c}\text { full-size sedan } \\
\begin{array}{c}\text { mid-size SUV } \\
\text { or pickup }\end{array}\end{array}$ & $37.5 \%$ & $20-30$ & 0.3 \\
$\begin{array}{c}\text { full-size SUV } \\
\text { or pickup }\end{array}$ & $10 \%$ & $30-40$ & 0.45 \\
\hline \hline
\end{tabular}

consumption per mile for the PEV, $\hat{D} w_{t}$ is the estimated workplace departure time and $\hat{A} w_{t}$ is the estimated workplace arrival time.

$$
\hat{P}_{P E V, i}=\frac{\hat{M}_{d} \times E_{m}}{\left(\hat{D} w_{t}-\hat{A} w_{t}\right)}
$$

The distributions of $\hat{M}_{d}, \hat{D} w_{t}$ and $\hat{A} w_{t}$ are essential to find the stochastic distribution of $\hat{P}_{P E V, i}$. Based on driving pattern statistics in the USA, a $\log$ normal distribution with $\mu_{m}=3.37$, $\sigma_{m}=0.5$ is selected to approximate the power density function (PDF) of $\hat{M}_{d}$. What's more, for this workplace car park, the PEVs arrival time and departure time obey normal distribution, with means equal to 9 and 18 and variances equal to 1.2 and 1.5 for arrival time and departure time respectively. By using MATLAB statistic distribution fitting toolbox and Monte Carlo simulation with 50000 samples, the PDF of power requirement for each PEVs when it is connected to this car park is found as an inverse Gaussian distribution with $\mu_{p}=1.573$ and $\lambda_{p}=3.652$. given in equation (5).

$$
f_{X}\left(x, \mu_{p}, \lambda_{p}\right)=\sqrt{\frac{\lambda_{p}}{2 \pi x^{3}}} \exp \left\{-\frac{\lambda_{p}}{2 \mu_{p}{ }^{2} x}\left(x-\mu_{p}\right)^{2}\right\}
$$

With equation (5), the power needed by the PEVs that will be connected to this car park for the next period can be calculated by using the following equation (6). Where NP is the total number of PEVs that may be connected to the car park,

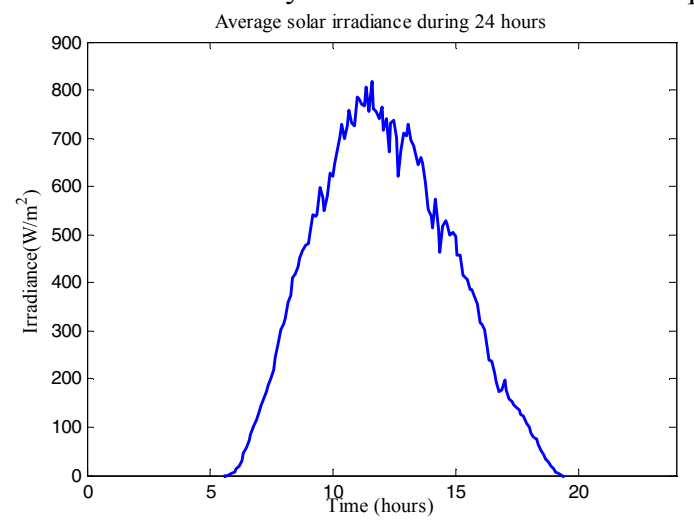

(a)

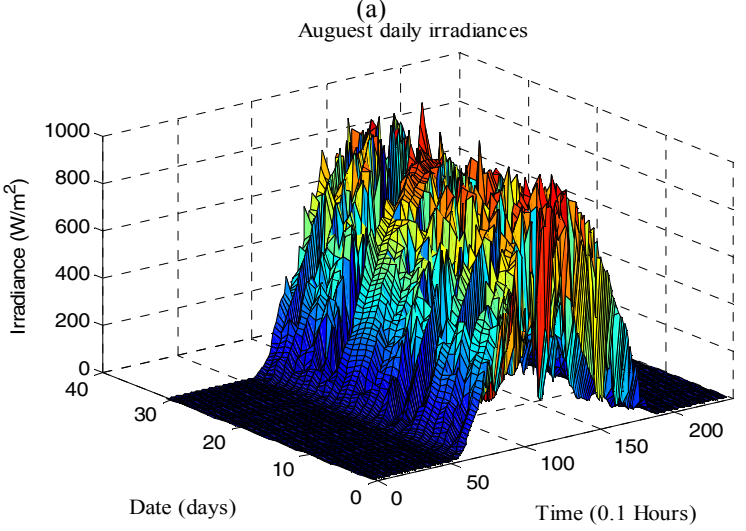

(b)

Fig.5. (a) one year average daily solar irradiance data, (b) daily solar irradiance data in august 


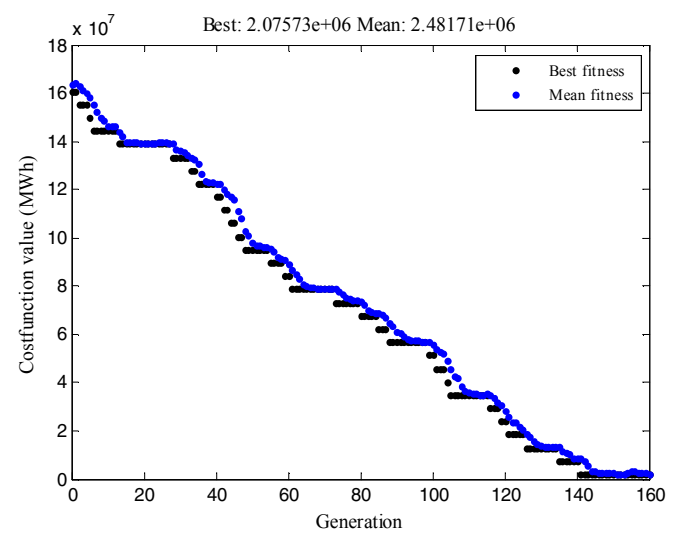

Fig. 6. PV farm scale optimization process through GA.

$f_{A t}\left(x, \mu_{A}, \sigma_{A}\right)$ is the PDF of grid connecting time $A_{t}$ and $\hat{P}_{P E V ~ a v g}$

is the average power requirement for PEVs when they connected to the car park, which can be calculated from equation (5).

$$
\hat{P}_{\text {upcoming }}=\int_{t}^{t+T} f_{A_{t}}\left(x, \mu_{A_{t}}, \sigma_{A_{t}}\right) d t \times N P \times \hat{p}_{\text {PHEV_avg }_{\text {avg }}}
$$

\section{B. PV farm scale optimization}

In this paper, the wind and solar data of the year 2007 in south Florida is used. The one year average daily solar irradiance data and daily solar irradiance data in august is shown in Fig 5. (a) and (b). The daily energy generated by solar panel can be calculated by using equation (7), in which $\mathrm{A}$ is the solar panel size and $\beta$ is the solar panel efficiency which is $22 \%$ in this paper.

$$
E_{\text {sloar }}=A \times \beta \int_{t=0}^{t=24} u(t) \times t d t
$$

For a PV farm with $A \mathrm{~m}^{2}$ of PV panel, a cost function of the gap between the PV farm output energy and total energy consumption for the PEVs in one year duration is expressed in equation (8), which can be used to optimize the scale of the PV farm through GA. The best solution is based on a proper $A$ that can minimize this cost function. It is shown that this renewable farm should contain $3343.30 \mathrm{~m}^{2}$ solar panels to generate proper energy for the $300 \mathrm{PEVs}$ daily consumption. For convenience, the system used $3350 \mathrm{~m}^{2}$ solar panels. The optimization process is shown in Fig. (6).

$$
f(A, N)=\sum_{d=1}^{d=365}\left|A \times \beta \int_{t=0}^{t=24} u(t) \times t d t-E_{P E V_{S}}(d)\right|
$$

Analysis of historical solar data covered that each day has its own distinct characteristics. For example, 7:00 PM in summer, the sun is still in the sky and PV panel still can generate power, but in winter it's completely dark and the solar irradiance will equal to zero. The same case will be for the early morning hours, for this reason short term forecasting becomes necessary.To forecast the next period output energy output from the optimized PV farm, artificial neural network(ANN) can be used. ANN is an information processing model that is inspired by the biological nervous systems, in the same way as the human brain process information. It is composed of a large number of highly interconnected processing elements (neurons) working in unison to solve specific problems. Since this paper
TABLE III

CHARGING RATES FOR DIFFERENT CHARGING LEVELS

\begin{tabular}{cccc}
\hline \hline Priority level & Power requirement & $\begin{array}{c}\text { Maximum } \\
\text { charging rate }\end{array}$ & $\begin{array}{c}\text { Minimum } \\
\text { charging rate }\end{array}$ \\
\hline Level 1 & $p \geq 15 k W$ & $12 \mathrm{~kW}$ & $12 \mathrm{~kW}$ \\
Level 2 & $10 k W \leq p<15 \mathrm{~kW}$ & $12 \mathrm{~kW}$ & $6 \mathrm{~kW}$ \\
Level 3 & $5 \mathrm{~kW} \leq p<10 k W$ & $8 \mathrm{~kW}$ & $0 \mathrm{~kW}$ \\
Level 4 & $2 \mathrm{~kW} \leq p<5 \mathrm{~kW}$ & $5 \mathrm{~kW}$ & $-5 \mathrm{~kW}$ \\
Level 5 & $p<2 k W$ & $2 \mathrm{~kW}$ & $-8 \mathrm{~kW}$
\end{tabular}

is not focused on ANN and forecasting, detail of ANN model and its application to solar energy forecasting is not covered.

\section{REAL Time PEVs CHARgING AlgORITHM}

To charge the PEVs smoothly, PEVs with a different state of charges (SOC) and power requirements should apparently be charged with different charging rates, which can greatly reduce the impact of PEVs' charging to the AC side. For example, comparing with the PEVs with high SOCs and will keep connecting to the grid for a long time, the charging power requirements for PEVs with low SOCs and will be disconnected from the grid shortly are much higher, which means the charging situation of those PEVs is more emergent. With the limited output power generated from the PV farm, those PEVs with high power charging requirement should be charged with a higher rate. The five charging priorities are shown in Table III. The minimum charging rates for PEVs in priority level 4 and 5 are negative values, which means they could be discharged under some situations. For example, at a certain time, PV farm can't support enough power for PEVs in level 1,2 and 3, but based on the forecasting, PV farm will generate enough energy for all the PEVs later, then instead of purchasing energy from the utility grid, the hybrid charging system can transfer some energy from the PEVs in level 4 and 5 to the PEVs in level 1,2 and 3. This is known as vehicle to vehicle (V2V) service.

During the whole day, all PEVs priorities are varying with their SOCs and departure time. Since the charging rate of the PEVs has no direct relationship with the renewable energy farm output power, it is not easy to use the classic controller to manage the power flow in the hybrid power system. To maximize the utilization of the energy generated by PV farm, an energy management algorithm based on fuzzy logic is designed. Fuzzy control is a powerful control method that can be applied on different systems. It is based on the experience of the user on the system behavior rather than modeling the system under control mathematically like in linear control theory. This makes fuzzy control a powerful control technique especially with non-linear systems in which it is difficult to derive an accurate approximated mathematical model of the system and expect its behavior. Fuzzy control is a rule based control technique that is approached by linguistic fuzzy rules, which describe the output desired out of the system under different operating conditions. Fuzzy rules are in the form of if-then rules that the proficient should design such that they cover all the conditions the system is expected to go through. Fuzzification, inference mechanism and defuzzification are 


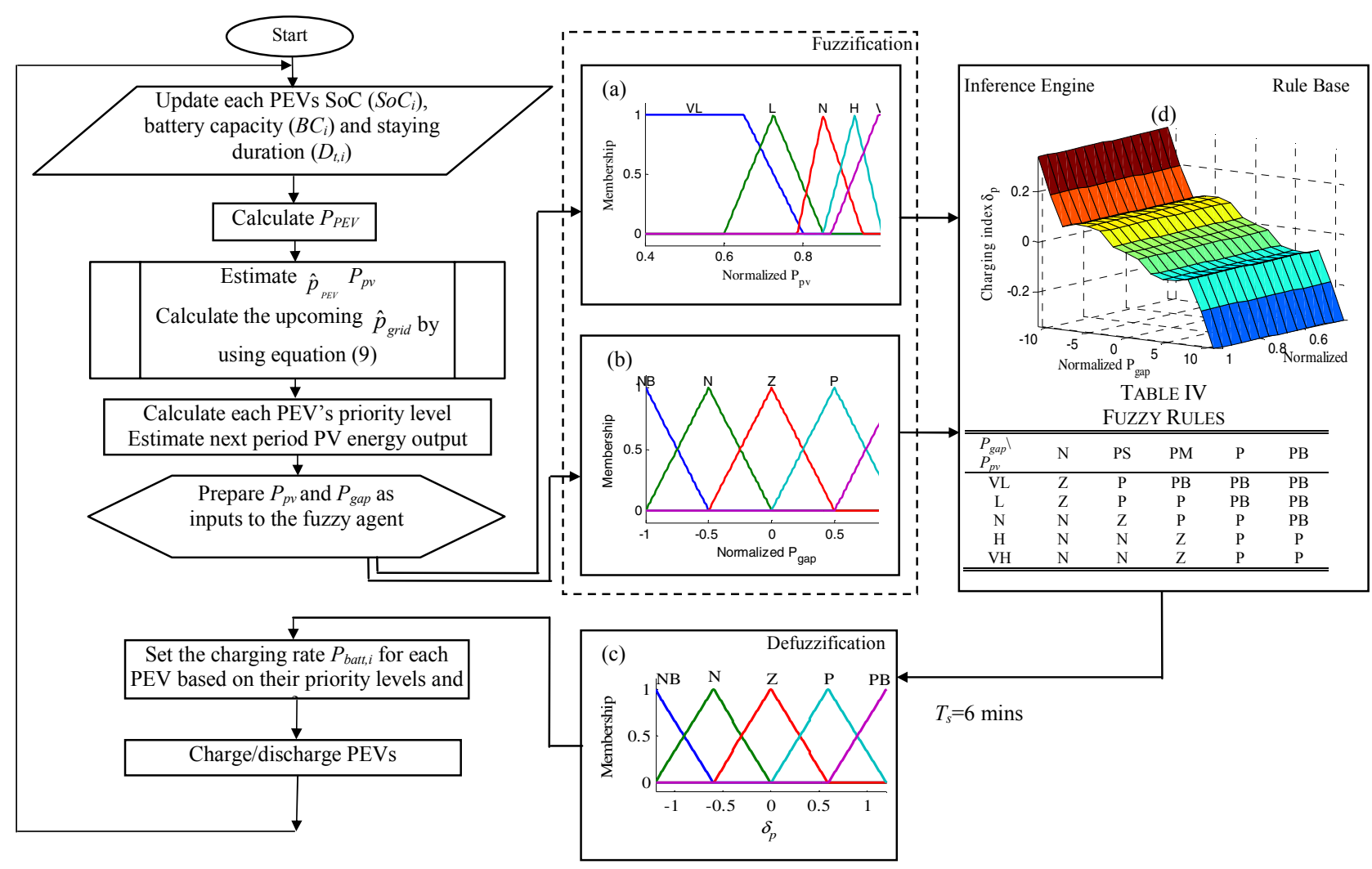

Fig. 7. A flow-chart showing the developed RTEMA.

three important steps in designing a fuzzy logic controller

The first input of the fuzzy logic controller is $P_{p v}$, the forecasted next period PV farm output energy coming from the forecasting result the neural network. The second input of fuzzy logic controller $P_{\text {gap }}$, is the forecasted energy gap between the output energy from the PV farm and the PEVs energy requirement for the rest of the day, which can be calculated by using equation (9), where $t_{\text {current }}$. is the current time.

$$
P_{\text {gap }}=A \times \beta \int_{t_{\text {current }}}^{t=24} u(t) \times t d t-\sum_{i=1}^{N}\left(\frac{0.8-S o C_{i}}{t_{\text {current }}-D w_{t i}}\right)
$$

The output of the fuzzy logic controller is the charging rate index $\delta_{P}$, which will adjust the charging rates of PEVs at different priority levels based on equation (10).

$$
P_{b a t t, i}= \begin{cases}12 & , \text { for level1 } \\ 9+3 \times \delta_{P} & , \text { for level 2 } \\ 4+4 \times \delta_{P} & , \text { for level3 } \\ 0+5 \times \delta_{P} & , \text { for level4 } \\ -3+5 \times \delta_{P} & , \text { for level 5 }\end{cases}
$$

The next period PV farm energy output: $P_{p v}$ is described as "very low", "low", "normal", "high" and "very high". Similarly, the energy gap $P_{\text {gap }}$ is described as "negative large", "negative", "zero", "positive", and "positive large". The method implemented for defuzzification is centroid based. Within the model, minimum and maximum are used for "AND" and "OR" operators, respectively. The charging rate index $\delta_{P}$ is described as "negative big", "negative", "zero", "positive" and "positive big". For convenience and simplify reasoning, the inputs and output are all normalized. The output $\delta_{P}$ is in the range of $[-1,1]$. After getting $\delta_{P}$, the charging of the PEVs in different level can be calculated. The flow chart of the real time smart charging algorithm is shown in Fig. 7

\section{SimUlation AND ANALYSIS}

In this section, a $300 \mathrm{~V}$ workplace parking garage hybrid power system equipped with a $3350 \mathrm{~m}^{2} \mathrm{PV}$ panel has 350 parking positions, and each work day around 300 PEVs will park in the garage during the work hour from 9AM to 6PM. Three experiments are done based on MATLAB Simulink. The first one is the simulation of PV farm MPPT based on P\&O shown in Fig. 8. The MPPT is enabled at $0.4 \mathrm{~s}$, before that the output power is around $96.16 \mathrm{~kW}$, which is less than the (maximum power point )MPP value as $100.71 \mathrm{~kW}$. Also, the boost converter with MPPT can adjust the output voltage to closely follow the MPP during the whole simulation process.

The second one is the PEVs charging power flow in the parking garage without real-time charging optimal control. The simulation result is shown in Fig. 9. In this case, whenever a $\mathrm{PEV}$ is connected to the parking garage, it will be charged with at a $10 \mathrm{~kW}$ charging rate and not stop charging until the SOC of its battery reach $80 \%$. From the simulation it is clear the peak happens around 9:00 AM because most of the PEVs arrive around this time every day. The peak last until 3:00 PM, but after that the charging power decrease sharply since most of the PEVs's SOCs already meet the requirement. The energy gap 


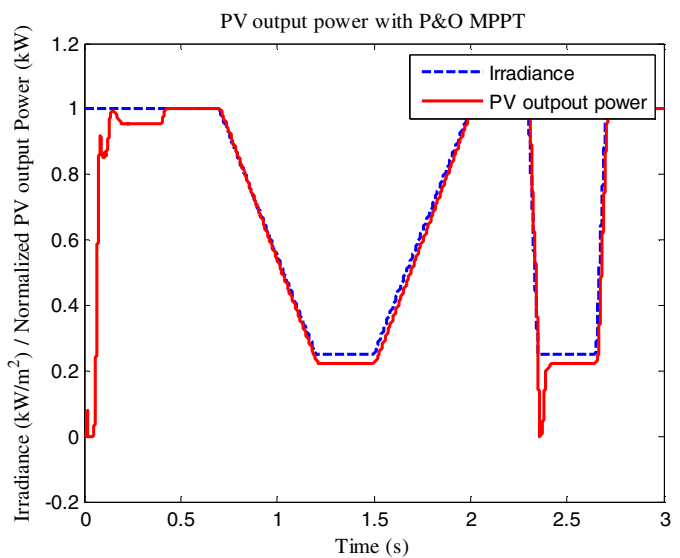

Fig. 8. MPPT by using P\&O method

between the PEVs charging power and PV output power in the morning need to be supported by the AC grid, which will bring impact to the $\mathrm{AC}$ grid. Also the energy gap in the afternoon will need the car park to inject power to the grid, all of these may influence the local AC grid frequency variation, meanwhile the power generated by the PV farm is not fully utilized.

The third one contains real-time fuzzy logic charging optimal control. The simulation result is shown in Fig. 10. In the second case, the fuzzy logic smart charging controller is applied to the system, and the PEVs charging can closely follow the changing of the output power from the PV farm. In this way, the car park power system doesn't need to absorb or inject too much power to the AC grid, which will limit the impact to the AC grid because this hybrid PEVs charging system can support PEVs' power requirement during the whole day by its PV, then it won't be a big load to the AC grid. Also, PEVs owners will pay less since most of the energy used to charge their PEVs is generated by the renewable energy sources. At the same time, this smart charging controller will maximize the utilization of the renewable energy from PV farm, this will decrease the fossil energy consumption, and consequently decrease the greenhouse gas emissions.

\section{CONCLUSION}

This paper presented a car park PV farm construction plan for charging 300 PEVs. GA is used to find the optimal size of the PV farm that can support proper power for the 300 PEVs.

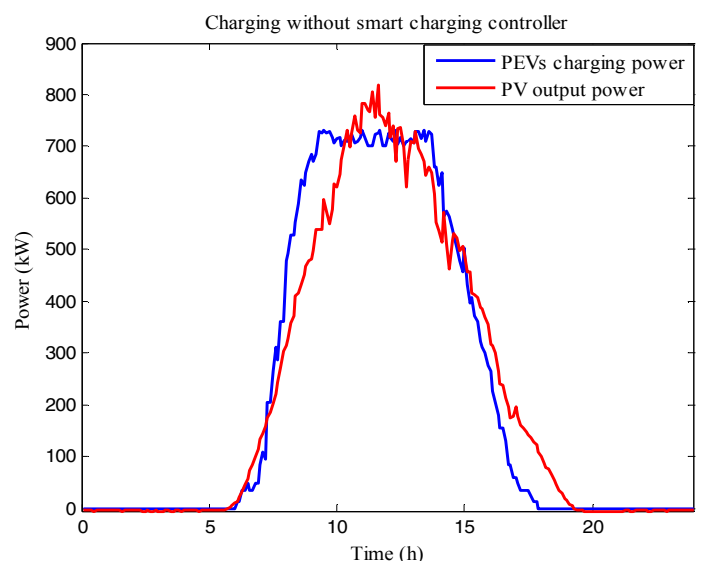

Fig. 9. PEVs charging power without real-time charging optimal control.

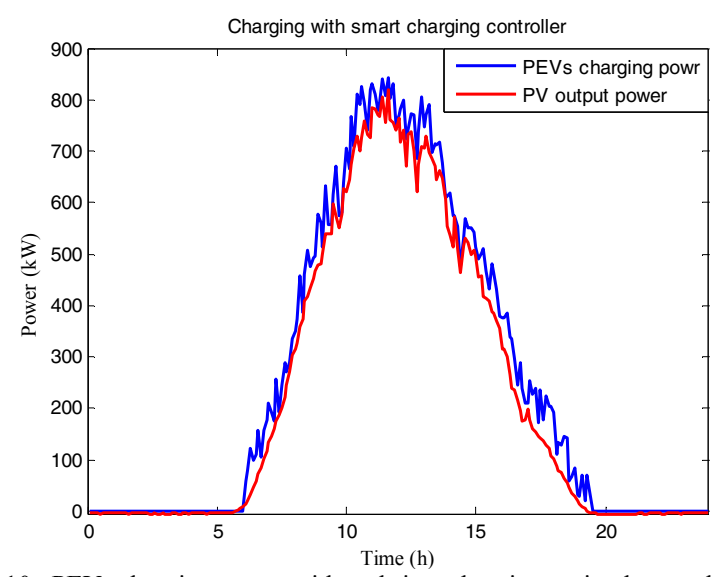

Fig. 10. PEVs charging power with real-time charging optimal control.

The PV panel model together with P\&O MPPT is given to maximize the energy harvesting from the PV farm. Based on the PV farm short term output power forecasted by ANN, together with the PEVs power requirement estimated by the stochastic model, a fuzzy logic smart charging controller is designed to maximize the utilization of PV farm output energy to charge the PEVs. The simulation of the PV farm system with P\&O MPPT and two PEVs charging cases with/without smart charging controller are done and analyzed. From the simulation results, the proposed PV construction plan can support enough power to the $300 \mathrm{PEVs}$ and at the same time limit the impact of PEVs charging to the utility $\mathrm{AC}$ grid and minimize the greenhouse gas emissions.

\section{REFERENCES}

[1] U.S. Energy Information Administration, "Annual Energy Review 2011" [Online] http://www.eia.gov/totalenergy/data/annual/pdf/aer.pdf

[2] J. Voelcker, "How Green Is My Plug-In?" Spectrum, IEEE, vol.46, no.3, pp.42-58, March 2009.

[3] "Technology roadmap: Electric and plug-in hybrid electric vehicles (EV/PHEV)," IEEE International Energy Agency (IEA), 2011

[4] T. Ma, A. Mohamed, and O. Mohammed. "Optimal charging of plug-in electric vehicles for a car park infrastructure." Industry Applications Society Annual Meeting (IAS), IEEE, 2012.

[5] S. Deilami, A.S. Masoum, P.S. Moses and M.A.S. Masoum, "Real-Time Coordination of Plug-In Electric Vehicle Charging in Smart Grids to Minimize Power Losses and Improve Voltage Profile," IEEE Transactions on Smart Grid, vol. 2, no. 3, pp. 456-467, September 2011.

[6] A. Anvari Moghaddam, A.R. Seifi, "Study of forecasting renewable energies in smart grids using linear predictive filters and neural networks, "Renewable Power Generation, IET, November 2011

[7] X. Liu, L. Ivanescu, K. Rui, M. Maier, "Real-time household load priority scheduling algorithm based on prediction of renewable source availability, "IEEE Transactions on Consumer Electronics, May 2012

[8] A Mohamed, C. C. Fernandez; T. Ma; M. Farhadi, O. Mohammed,"Operation and protection of photovoltaic systems in hybrid AC/DC smart grids," IECON 2012 - 38th Annual Conference on IEEE Industrial Electronics Society, vol., no., pp.1104-1109, 25-28 Oct. 2012

[9] M. E. Ropp and S. Gonzalez,"Development of a MATLAB/simulink model of a single-phase grid-connected photovoltaic system," IEEE Trans. Energy Conv., VOL. 24, NO. 1, PP. 195-202, MAR. 2009.

[10] K. H. Chao, C. J. Li, and S. H. Ho, "Modeling and fault simulation of photovoltaic generation systems using circuit-based model," in Proc. IEEE Int. Conf. Sustainable Energy Technol., Nov. 2008, pp. 290-294. 